\title{
An Evaluation of the Anti-neoplastic Activity of Curcumin in Prostate Cancer Cell Lines
}

\author{
Camila B. Piantino, Fernanda A. Salvadori, Pedro P. Ayres, Raphael B. Kato, Victor Srougi, \\ Katia R. Leite, Miguel Srougi
}

Laboratory of Medical Investigation (CBP, FAS, PPA, RBK, VS, KRL, MS), Department of Urology, School of Medicine, Sao Paulo University, SP, Brazil, Laboratory of Surgical and Molecular Pathology (KRL), Sirio Libanes Hospital, Sao Paulo, and Genoa Biotechnology AS (KRL), Sao Paulo, SP, Brazil

\begin{abstract}
Objective: The aim of our study is to investigate the anti-neoplastic effect of curcumin in prostate cancer cell lines. Specifically, we are using the LNCaP cell line and another prostate cell line developed in our laboratory, PcBra1. The PcBra1 cells were derived from a localized, obstructive prostate cancer with a Gleason score of $9(4+5)$.

Materials and Methods: A prostate cancer cell line was isolated from a localized, obstructive prostate cancer with a Gleason score of $9(4+5)$, and it was characterized using immunohistochemistry. After six passages, the new cell line was treated with varying doses of curcumin: $10 \mu \mathrm{M}, 25 \mu \mathrm{M}$ or $50 \mu \mathrm{M}$. Apoptosis was detected by flow cytometry using Annexin V FITC. For comparison, the same experiment was performed using the well-established metastatic prostate cancer cell line, LNCaP.

Results: Increasing concentrations of curcumin promoted more apoptosis in the PcBral cells. Exposure to 10 and $25 \mu \mathrm{M}$ curcumin induced apoptosis in $31.9 \%$ and $52.2 \%$ of cells, respectively. Late apoptosis was induced in $37 \%$ of cells after treatment with $10 \mu \mathrm{M}$ curcumin and $35 \%$ of cells with a $25 \mu \mathrm{M}$ treatment. Necrosis accounted for less than $10 \%$ of the death in these cells at those two concentrations. When curcumin was used at $50 \mu \mathrm{M}$, apoptosis was observed in $64.3 \%$ of the cells. Including late apoptosis and necrosis, $98.6 \%$ of the cells died in response to $50 \mu \mathrm{M}$ curcumin. Results with the LNCaP cells were similar although late apoptosis was the main phenomenon at $25 \mu \mathrm{M}$.

Conclusion: We have shown that curcumin acts on localized prostate cancer to induce apoptosis and may therefore be an option as a future therapeutic agent.
\end{abstract}

Key words: curcumin; curcuma longa; prostate cancer; apoptosis

Int Braz J Urol. 2009; 35: 354-61

\section{INTRODUCTION}

Prostate cancer (PC) is the most common cancer in Brazilian men and the second leading cause of death. The annual incidence of prostate cancer in Brazil continues to rise, and 49,530 new cases were predicted for 2008 (1). Advanced prostate cancer is treated with anti-androgens, but after 2 to 3 years of therapy, neoplasia often becomes hormone resistant and is usually no longer responsive to conventional chemotherapy. As a consequence, many prostate cancer patients are drawn toward alternative therapies (2). In fact, a majority of patients at major medical centers are now combining their conventional therapies with some form of alternative and complementary medicine, the most popular of which involve nutri- 
tional modifications and the use of herbal and other micronutrients (3).

Curcumin [1,7-bis(4-hydroxy-3-methoxy phenyl)-1,6-heptadiene-3,5-dione] is a phenolic compound and is the main ingredient of Curcuma longa. It is extracted as a yellow pigment from the rhizome, which has been used extensively in curries and mustards. Anti-inflammatory, anti-oxidant, and anti-septic effects of curcumin have been reported (4). Curcumin seems to elicit positive results in such a wide variety of ways because of its capability to act as free radical scavenger (5). Additionally, curcumin can alter the gene expression patterns of various stress-induced proteins and genes involved in angiogenesis (6). Finally, curcumin can inhibit the activity of many important transcription factors, such as NFkB and AP-1 (7).The effects of curcumin depends on its concentration. At $10 \mu \mathrm{M}$, it acts as an anti-oxidant (8), and at $50 \mu \mathrm{M}$ it generates superoxide radicals and induces apoptosis (9). The aim of our study was to examine the anti-neoplastic effect(s) of curcumin in two prostate cancer cell lines, LNCaP and a prostate cell line developed in our laboratory from a localized, obstructive, androgen-independent prostate cancer with a Gleason score of $9(4+5)$.

\section{MATERIALS AND METHODS}

\section{Materials}

Culture medium consisted of RPMI-1640 supplemented with fetal bovine serum (FBS), streptomycin, and penicillin (all from GIBCO, Rockville, MD, USA). Curcumin was purchased from Calbiochem (La Jolla, CA). A $100 \mathrm{mM}$ stock solution was prepared in dimethyl sulfoxide (DMSO, Sigma Chemical, St. Louis, MO, USA) and stored at $4^{\circ} \mathrm{C}$. Fresh solutions were made by diluting the stock into cell culture medium immediately before use. Annexin V FITC and Propidium Iodide (PI) were purchased from BD-Pharmingen (San Jose, CA, USA) and Sigma Chemical (St. Louis, MO, USA) respectively.

\section{LNCaP Cell Culture}

The LNCaP (FGC clone) cells were obtained from American Type Culture Collection (Rockville,
MD, USA) and were cultivated in RPMI-1640 medium supplemented with $10 \% \mathrm{FBS}$, streptomycin 100 $\mathrm{mg} / \mathrm{mL}$, and penicillin $100 \mathrm{U} / \mathrm{mL}$ at $37^{\circ} \mathrm{C}$ in a $5 \% \mathrm{CO}_{2}$ humidified incubator.

\section{Establishment of Cell Line}

The PcBral prostate adenocarcinoma cell line was established from a 62-year-old white male, who underwent a transurethral resection in August 2006 for an obstructive, androgen-independent cancer with a Gleason score of 9(4+5). Specimens of the prostate adenocarcinoma were obtained immediately after the resection and transported in RPMI-1640 medium. The tissue was sectioned and digested using type VIII collagenase at $0.56 \mathrm{mg} / \mathrm{mL}$ (Sigma Chemical, St. Louis, MO, USA). Cell suspensions were subdivided into 25 $\mathrm{cm}^{2}$ tissue culture flasks containing RPMI-1640 supplemented with $10 \% \mathrm{FBS}$, streptomycin $(100 \mathrm{mg} / \mathrm{mL})$, and penicillin $(100 \mathrm{U} / \mathrm{mL})$ in a $5 \% \mathrm{CO}_{2}$ humidified incubator. The medium was changed twice weekly or until a confluent monolayer was established. At the time of confluence, adherent cells were subcultured after detachment using trypsin/EDTA( $0.25 \%$ trypsin$1.0 \mathrm{mM}$ ethylenediaminetetraacetate).

In order to eliminate fibroblast contamination, we submitted the cell culture to (1) nutritional starvation (S) and (2) cell differential attachment (DA):

\section{Nutritional Starvation (s)}

Tumor cell colonies were exposed to media with a reduced concentration of serum. Serum reduction was gradual, starting with $10 \%$, then $5 \%, 2.5 \%$, and finally $1 \%$. Incubation with each concentration of serum lasted about 1 week. The last step (1\% FBS) was continued until dense tumor cell colonies became evident.

\section{Differential Attachment (DA)}

Tumor cell colonies were trypsinized, resuspended in $10 \mathrm{~mL}$ of media (10\% FBS), reseeded and incubated for 15 minutes in the original flask (first cycle). At the end of the first cycle, nonadherent cells were transferred to a new flask, which was incubated for an additional 15 minutes (second cycle). The first 
flask was mostly composed of fibroblasts, while the last flask contained mostly tumor cells. At confluence, if the fibroblasts were not totally eliminated, the cell growth from the $4^{\text {th }}$ cycle was harvested, and the entire procedure was repeated.

\section{Characterization of Cell Culture by Immunocytochemistry}

The primary cancer cell culture PcBral was characterized as prostate primary by immunocytochemistry using anti-Prostate Specific Membrane Antigen (clone P, dilution 1:100; Santa Cruz, Santa Cruz, CA, USA) and pan-cytokeratins (Dilution 1:100, Dako, Glostrup, Denmark) antibodies. To certify the absence of fibroblast and endothelial cell contamination, anti-desmin (clone D33, dilution 1:100; Dako, Glostrup, Denmark) and anti-factor VIII (clone F8/86, dilution 1:400; Dako, Glostrup, Denmark) antibodies were also utilized to stain these cells. Briefly, cells were recovered from culture flasks using a cell scraper and fixed in $70 \%$ alcohol following a $900 \mathrm{~g}$ centrifugation for 5 minutes at room temperature. The cytocentrifugate was impressed on adhesive coated slides and incubated overnight at $4{ }^{\circ} \mathrm{C}$ with the antibodies mentioned above. Next, biotinylated anti-mouse immunoglobulin $\mathrm{G}$ was applied at a 1:200 dilution for 60 minutes at room temperature. Slides were rinsed with PBS for 30 minutes, incubated with peroxidase-conjugated streptavidin (streptABC Kit, Dako, Glostrup Denmark) at a 1:400 dilution in PBS for 45 minutes at room temperature, and rinsed with PBS for 30 minutes. Color was developed by incubating the slides with $0.06 \%$ diaminobenzidine in PBS for 15 minutes. Slides were then rinsed in tapwater, counterstained with Harris hematoxylin, dehydrated, coverslipped, and reviewed under a light microscope.

\section{Chemosensitivity Studies}

PcBral from passage 6 and $\mathrm{LNCaP}$ cell cultures $\left(2 \times 10^{5} / \mathrm{mL}\right)$ were incubated with curcumin at $10 \mu \mathrm{M}, 25 \mu \mathrm{M}$ and $50 \mu \mathrm{M}$ for $24 \mathrm{~h}$. After incubation, cells were harvested and resuspended with 100 $\mu \mathrm{L}$ of buffer solution (10 mM Hepes; $150 \mathrm{mM} \mathrm{NaCl}$; $\left.5 \mathrm{mM} \mathrm{KCl}, 1 \mathrm{mM} \mathrm{MgCl}, 1.8 \mathrm{mM} \mathrm{CaCl}_{2 ;} \mathrm{pH}=7.4\right)$. Annexin V FITC (dilution 1:500, BD-Pharmingen,
San Jose, CA, USA) was added and the suspension was incubated for 20 minutes at room temperature. To perform a double stain, $400 \mu \mathrm{L}$ of buffer and 40 $\mu \mathrm{L}$ of PI (SigmaChemical, St. Louis, MO, USA) were added to the sample. The percentage of cells in apoptosis and necrosis was determined by flow cytometry (FACScalibur, Becton Dickinson Immunocytometry Systems, San Jose, CA, USA). Ten thousand events were analyzed using the Cell Quest Pro software (Becton Dickinson Immunocytometry System, San Jose, CA, USA).

\section{RESULTS}

The PCBral cell line was derived from an obstructive, androgen-independent prostate adenocarcinoma. The tumor was confirmed to be a prostate epithelial cell malignancy through positive staining for PSMA and cytokeratin. To aid in the analysis, and exclude the possibility of fibroblast contamination we also used antibodies for anti-desmin and anti-factor VIII, which specifically stain for fibroblasts and endothelial cells, respectively (Figure-1). PCBra1 stained negatively for these markers. The generation time (g) was calculated using the formula $\mathrm{n}=(3.32 \log \mathrm{Xf} / \mathrm{Xi})$ / Tf - Ti, being $\mathrm{g}=1 / \mathrm{n}$, and for PCBra1 the doubling time was $50 \mathrm{~h}$. The cariotype reveled that the majority of cells were aneuploid and the most frequent occurrence was loss of chromosomes. We also performed studies in PCBral cells to examine the chemosensitivity to increasing curcumin concentrations. For comparison, we also studied the ability of curcumin to induce cell death in a well-established prostate cancer cell line $\mathrm{LNCaP}$, derived from a metastatic prostate carcinoma to a lymph node, androgen-dependent. As shown in Figure-2A, Annexin V positive cells (R1) were characterized as apoptotic cells. PI positive cells (R4) were considered necrotic, and double stained cells (R2) were labeled as late apoptotic cells.

Our results revealed that $\mathrm{PCBra} 1$ cell viability decreases in response to the three increasing concentrations of curcumin tested (Figure-2B). Exposure of the cells to $10 \mu \mathrm{M}$ or $25 \mu \mathrm{M}$ curcumin induced apoptosis in $31.9 \%$ and $52.2 \%$ of cells, respectively. Those same concentrations led to late apoptosis in $37 \%$ and $35 \%$ of cells. The number of cells undergoing necrosis 

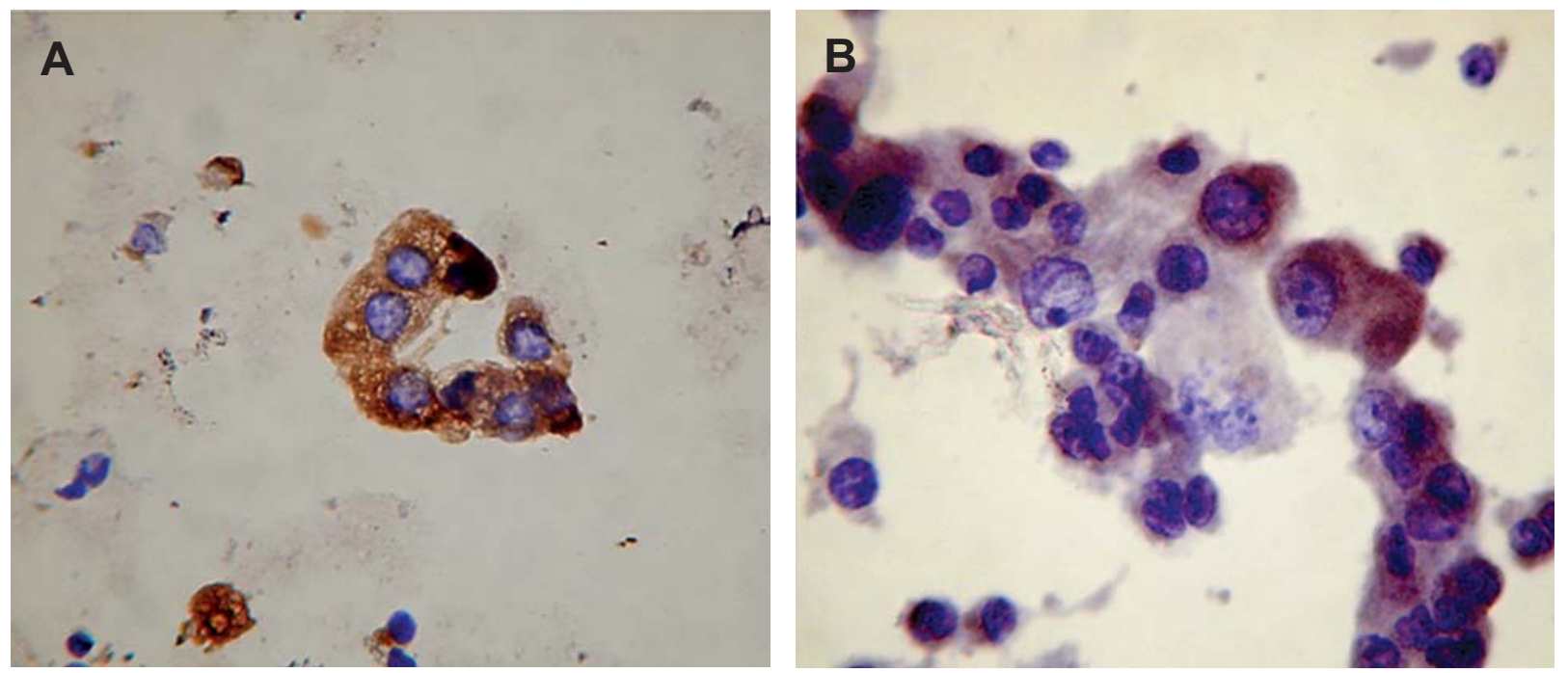

Figure 1 - Immunocytochemistry results of PcBral cell line. A) Expression of PSMA. B) Cytokeratins, confirming the epithelial phenotype and prostate origin. Vimentin and desmin were negative eliminating the possibility of fibroblast or endothelial cell contamination.

was lower, less than $10 \%$ at the two concentrations mentioned above. When curcumin was used at $50 \mu \mathrm{M}$, apoptosis was the most common process identified, as $64.3 \%$ of cells seemed to be dying by apoptosis. Late apoptosis was the next most common form of death, as $34 \%$ of the cells were classified this way. Overall, $98.6 \%$ of the cells were dying, and necrosis only accounted for $0.35 \%$ of this cell population.

Analysis of LNCaP cells also showed enhanced apoptosis and a decrease in necrosis after treatment with increasing concentrations of curcumin. As shown in Figure-2B, at $50 \mu \mathrm{M}$ curcumin, almost $90 \%$ of the cells were undergoing apoptosis. However, in contrast to the behavior of the PcBral cells, the $\mathrm{LNCaP}$ cells in late apoptosis continued to increase, reaching $63 \%$ with $25 \mu \mathrm{M}$ curcumin. At $50 \mu \mathrm{M}$, the late apoptotic population was reduced to $9 \%$ of the cells.

\section{COMMENTS}

In this study, we investigated the anti-neoplastic effect of curcumin on a prostate cancer cell line developed in our laboratory. We call this line PCBra1, and it originated from a localized PC. The results of our study demonstrate that at concentrations of 10 $\mu \mathrm{M}, 25 \mu \mathrm{M}$ and $50 \mu \mathrm{M}$, curcumin induced apoptosis in increasing proportions of cells: $31.9 \%, 52.2 \%$ and $64.3 \%$ respectively. The percentage of cells undergoing necrosis was lower, less than $10 \%$, and the amount of cells in late apoptosis was variable between $34.0 \%$ and $37.0 \%$, with an overall cell death of $98.6 \%$. When we compared these results to a metastatic cell line of $\mathrm{PC}, \mathrm{LNCaP}$, the results were very similar. More tumor cells underwent apoptosis as the concentration of curcumin increased. At $50 \mu \mathrm{M}$, almost $90 \%$ of the cells had undergone apoptosis.

Curcumin induces apoptosis through ROSdependent pathway, caspase activation and inhibiting Bcl-2 family members (10). One intriguing fact that we have observed in this study was a decreasing number of necrotic cells as long as the apoptosis rises under increasing concentrations of curcumin. We can hypothesize that curcumin could be acting over other proteases than caspases, not yet characterized, that under lower concentration lead to necrosis as an alternative of apoptosis. This should be motive of further studies.

These results identify similarities in the behavior of the two cell lines. It is important to mention that the cell line established by us, PCBra1, was derived from an obstructive, localized, androgenindependent prostate adenocarcinoma, while the LNCaP cells are originally from a metastatic site and androgen-dependent prostate cancer. DU-145 and 
A
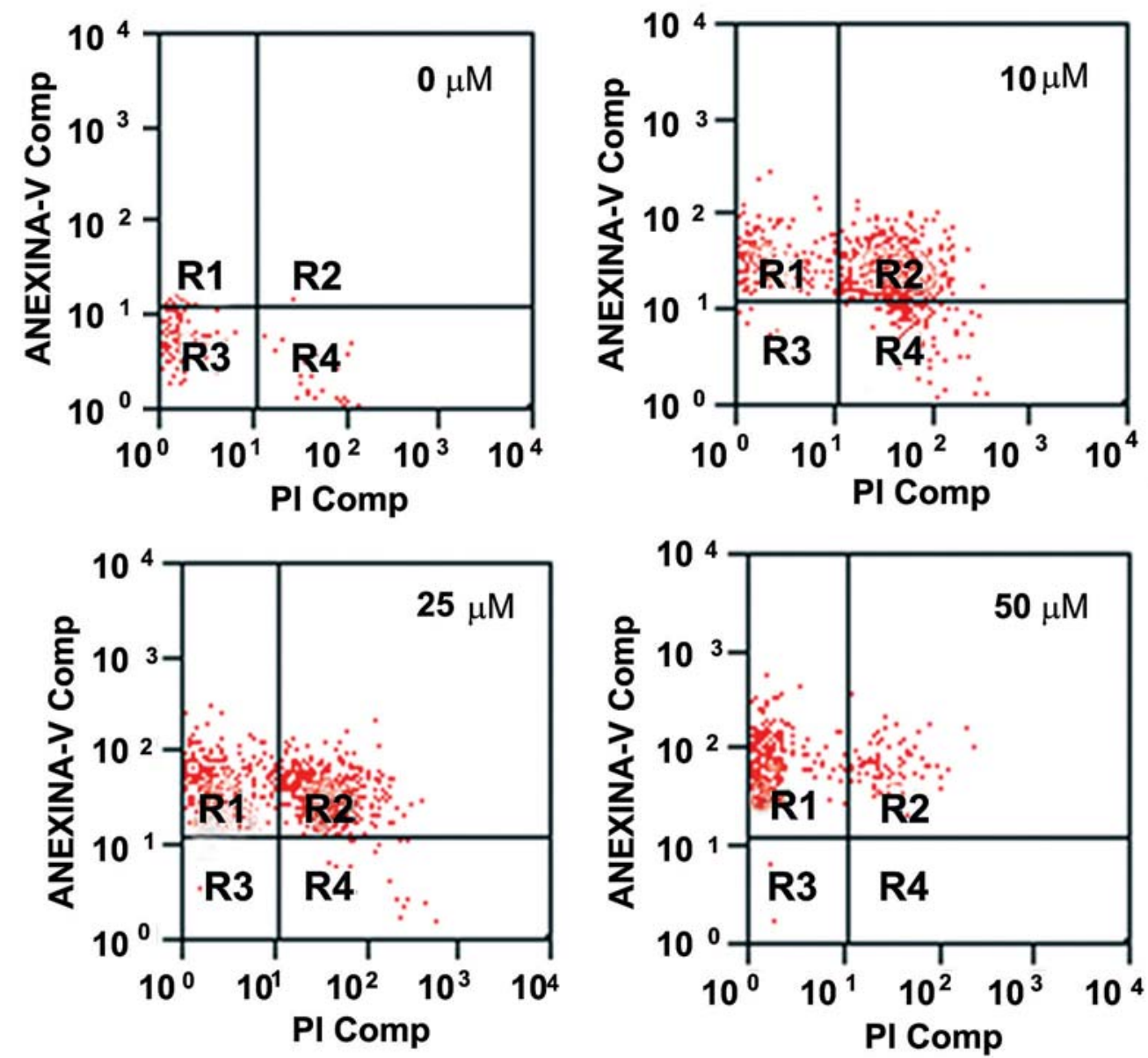

B

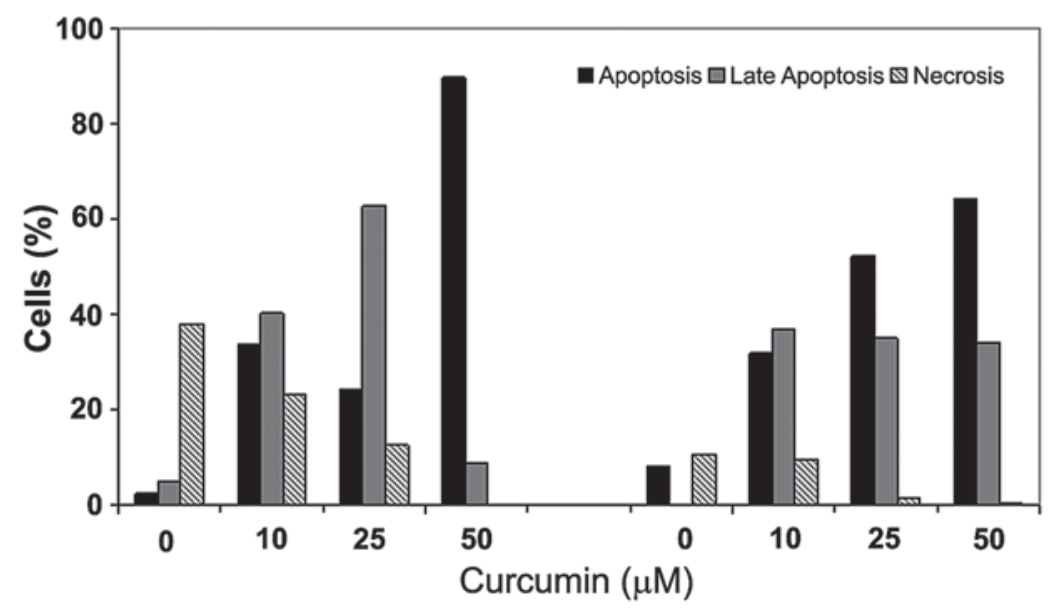

LNCaP

\section{PcBra1}

Figure 2 - Curcumin effects on cell viability. LNCaP and PcBral were incubated with or without curcumin and stained with Annexin $V$-FITC and Propidium Iodide (PI) followed by flow cytometry analysis. A) Schematic representation of results; $R I=$ cells marked with Annexin (apoptosis); R2 = cells marked with Annexin and PI (late ptosis); R3 = no marked cells (viable) and R4 = cells stained with PI (necrosis). B) Percentage of cells in apoptosis, late apoptosis and necrosis after treatment with increasing concentrations of curcumin for 24 hours. 
PC-3 cells are other classical prostate cancer cell lines (11-13) used in the majority of in vitro investigations, and they also originated from metastatic sites. While it is true that these classical cell lines have been helpful in understanding advanced stages of the disease, the establishment and characterization of a localized prostate carcinoma cell line remains very important, since it represents a different stage and behavior of this particular neoplasia. The few cell lines that were isolated from primary prostate carcinoma tissues and have been characterized in the literature were found to actually be derivatives of other metastatic prostate cancer cell lines (e.g., ND-1 from DU-145) $(14,15)$ or contamination of other cell types (PEAZ-1 in HT-1080) (16,17). Moreover, the differences among various populations and racial differences in prostate cancer justify the necessity for the establishment and characterization of human prostate tumor cell lines from Brazilian patients for further experiments with different drugs and molecules.

Dorai et al. (18) examined the effect of curcumin on EGF receptor signaling in the androgensensitive LNCaP and androgen-insensitive PC-3 cell lines. They found that curcumin was a potent inhibitor of EGF-R signaling, and it accomplished this effect in three different ways: (1) down-regulation the EGF-R protein; (2) inhibition of the intrinsic EGF-R tyrosine kinase activity; and (3) inhibition of ligand-induced activation of the EGF-R. This group concludes that curcumin can induce apoptosis in this model by interfering with the signal transduction pathways of a prostate cancer cell.

Curcumin is a phenolic compound, and it is the major ingredient in the rhizome of the herb Curcuma longa. The use of turmeric as a medicinal compound dates back to around $2000 \mathrm{BC}$ when it was used as an anti-inflammatory agent. With time, more and more of its medicinal uses were discovered, and today, curcumin is associated with a plethora of beneficial effects on human health. Most recently, curcumin has been used as an anti-inflammatory, anti-mutagenic (19), and anti-cancer substance (20). It works as an anti-oxidant and is capable of inducing apoptosis $(21,22)$.

The possible mechanisms responsible for the induction of apoptosis by curcumin are varied, including effects on the stability and super-expres- sion of p53 (23), the release of cytochrome c, and the induction of reactive oxygen intermediates (24). It has previously been described that curcumin can suppress NF-k $\beta$, Akt, AP-1 or JNK. It can also affect gene expression; curcumin can up-regulate the genes related to the DNA damage response (25) and down-regulate genes related to cell survival, such as egr-1, c-myc, and bclX(L). Shankar et al. (26) have recently shown that curcumin inhibits growth and induces apoptosis in androgen-dependent and -independent prostate cancer cells by downregulating the expression of $\mathrm{Bcl}-2$ and $\mathrm{Bcl}-\mathrm{XL}$ and upregulating the expression of p53, Bax, Bak, PUMA, Noxa, and Bim. Curcumin also affected p53 by modulating its phosphorylation at serine 15 and its acetylation in a concentration-dependent manner.

In conclusion, we have shown that curcumin is a substance that can act in cells isolated from localized PC, inducing apoptosis as it does in metastatic cell lines. Pathways involved in this phenomenon are not yet clarified, and the next steps of our study will address some of these questions. At this time, we can speculate that curcumin or its components could be used to treat localized or metastatic prostate cancer, and further studies should be performed to elucidate the specific mechanism by which curcumin is able to induce some of these anti-cancer phenotypes.

\section{CONFLICT OF INTEREST}

None declared.

\section{REFERENCES}

1. Available at: http/www.inca.gov.br

2. Moyad MA: Alternative therapies for advanced prostate cancer. What should I tell my patients? Urol Clin North Am. 1999; 26: 413-7.

3. Denis L, Morton MS, Griffiths K: Diet and its preventive role in prostatic disease. Eur Urol. 1999; 35: 377-87.

4. Hergenhahn M, Soto U, Weninger A, Polack A, Hsu $\mathrm{CH}$, Cheng AL, et al.: The chemopreventive compound curcumin is an efficient inhibitor of Epstein-Barr virus BZLF1 transcription in Raji DR-LUC cells. Mol Carcinog. 2002; 33: 137-45. 
5. Kato K, Ito H, Kamei K, Iwamoto I: Stimulation of the stress-induced expression of stress proteins by curcumin in cultured cells and in rat tissues in vivo. Cell Stress Chaperones. 1998; 3: 152-60.

6. Mohan R, Sivak J, Ashton P, Russo LA, Pham BQ, Kasahara N, et al.: Curcuminoids inhibit the angiogenic response stimulated by fibroblast growth factor2 , including expression of matrix metalloproteinase gelatinase B. J Biol Chem. 2000; 275: 10405-12.

7. Woo MS, Jung SH, Kim SY, Hyun JW, Ko KH, Kim WK, et al.: Curcumin suppresses phorbol ester-induced matrix metalloproteinase-9 expression by inhibiting the PKC to MAPK signaling pathways in human astroglioma cells. Biochem Biophys Res Commun. 2005; 335: 1017-25.

8. Cheng AL, Hsu CH, Lin JK, Hsu MM, Ho YF, Shen TS, et al.: Phase I clinical trial of curcumin, a chemopreventive agent, in patients with high-risk or pre-malignant lesions. Anticancer Res. 2001; 21: 2895-900.

9. Orlowski RZ, Baldwin AS Jr: NF-kappaB as a therapeutic target in cancer. Trends Mol Med. 2002; 8: 385-9.

10. Skommer J, Wlodkowic D, Pelkonen J: Cellular foundation of curcumin-induced apoptosis in follicular lymphoma cell lines. Exp Hematol. 2006; 34: 463-74.

11. Schmelz M, Cress AE, Barrera J, McDaniel KM, Davis TL, Fuchs L, et al.: PEAZ-1: a new human prostate neoplastic epithelial cell line. Prostate. 2001; 48: 7992. Erratum in: Prostate. 2004; 61: 375.

12. Erratum: Monika Schmelz, Anne E. Cress, Jean Barrera, Kathy M. McDaniel, Tracy L. Davis, Laura Fuchs, Bruce L. Dalkin, Raymond B. Nagle. PEAZ-1: A new human prostate neoplastic epithelial cell line. Prostate 2001;48:79-92. Prostate. 2004; 61: 375.

13. Rhim JS: In vitro human cell culture models for the study of prostate cancer. Prostate Cancer Prostatic Dis. 2000; 3: 229-235.

14. Ko D, Gu Y, Yasunaga Y, Nakamura K, Srivastava S, Moul JW, et al.: A novel neoplastic primary tumor-derived human prostate epithelial cell line. Int J Oncol. 2003; 22: 1311-7.

15. Steck PA, Pershouse MA, Jasser SA, Yung WK, Lin H, Ligon AH, et al.: Identification of a candidate tumour suppressor gene, MMAC1, at chromosome 10q23.3 that is mutated in multiple advanced cancers. Nat Genet. 1997; 15: 356-62.

16. Li J, Yen C, Liaw D, Podsypanina K, Bose S, Wang SI, et al.: PTEN, a putative protein tyrosine phosphatase gene mutated in human brain, breast, and prostate cancer. Science. 1997; 275: 1943-7.
17. Isaacs WB, Carter BS, Ewing CM: Wild-type p53 suppresses growth of human prostate cancer cells containing mutant p53 alleles. Cancer Res. 1991; 51: 4716-20.

18. Dorai T, Gehani N, Katz A: Therapeutic potential of curcumin in human prostate cancer. II. Curcumin inhibits tyrosine kinase activity of epidermal growth factor receptor and depletes the protein. Mol Urol. 2000; 4: 1-6.

19. Stoner GD, Mukhtar H: Polyphenols as cancer chemopreventive agents. J Cell Biochem Suppl. 1995; 22: 169-80.

20. Kuttan R, Bhanumathy P, Nirmala K, George MC: Potential anticancer activity of turmeric (Curcuma longa). Cancer Lett. 1985; 29: 197-202.

21. Kuo ML, Huang TS, Lin JK: Curcumin, an antioxidant and anti-tumor promoter, induces apoptosis in human leukemia cells. Biochim Biophys Acta. 1996; 1317: 95-100.

22. Khar A, Ali AM, Pardhasaradhi BV, Begum Z, Anjum $\mathrm{R}$ : Antitumor activity of curcumin is mediated through the induction of apoptosis in AK-5 tumor cells. FEBS Lett. 1999; 445: 165-8.

23. Scott DW, Loo G: Curcumin-induced GADD153 gene up-regulation in human colon cancer cells. Carcinogenesis. 2004; 25: 2155-64.

24. Aggarwal BB, Kumar A, Bharti AC: Anticancer potential of curcumin: preclinical and clinical studies. Anticancer Res. 2003; 23: 363-98.

25. Han SS, Chung ST, Robertson DA, Ranjan D, Bondada $\mathrm{S}$ : Curcumin causes the growth arrest and apoptosis of B cell lymphoma by downregulation of egr-1, c-myc, bcl-XL, NF-kappa B, and p53. Clin Immunol. 1999; 93: 152-61.

26. Shankar S, Srivastava RK: Involvement of Bcl-2 family members, phosphatidylinositol 3'-kinase/AKT and mitochondrial p53 in curcumin (diferulolylmethane)induced apoptosis in prostate cancer. Int J Oncol. 2007; 30: 905-18.

Accepted after revision: January 21, 2009 


\section{EDITORIAL COMMENT}

An amazing number of papers investigating the actions, mechanisms and clinical effects of curcumin, an old Indian spice, have been published over the last 15 years. Curcumin belongs to the so called polyphenolic compounds extracted from the plants that were used for medications since a long time ago. An exceptional property of curcumin seems to be its real beneficial effect in many different diseases which sometimes is hard to apprehend. How can it be, that curcumin is neuron-protective, acting anti-apoptotic, so that it can be considered as Alzheimer-preventing stuff on one hand, and induces apoptosis of cancer cells, on the other hand, while normal, healthy cells remain inviolate? Is curcumin one of "God's blessings" for our life?

The issue is a complex one, as more than 40 different targets of curcumin have been documented including enzymes, growth and transcription factors, protein kinases and chemokines (1). Therefore, a reasonable rationale for its action is still to be established. This is due to the fact that most targets described so far are secondary cellular response maskers which do not directly interact with curcumin. Noteworthy, is the recent paper by Santel et al. (2) which has added "the first line target" to the plethora of curcumin's actions. Inhibition of glyoxalases, involved in glycolytic pathway could be an explanation for curcumin's bias to target cancer cells.

In this regard, Piantino et al. presented important pre-clinical studies, demonstrating for the first time, to the best of my knowledge, the effect of curcumin on the primary prostate cancer cells. The authors clearly demonstrated that curcumin within a concentration range between 10 to $50 \mu \mathrm{M}$ induces cell death primarily through apoptosis. Additionally, the authors showed the process of how to test primary cancer cells for their susceptibility to interact with a drug. In combination with biopsies, such a procedure can be applied for selection of the most potent chemotherapeutics having the lowest side effects. In this line, this plant-derived mysterious substance could be advantageous over known registered anti-tumor drugs. This warrants further clinical studies to compare such nutraceuticals as curcumin with other therapeutic approaches.

However, one of the important questions to be addressed is "how to bring curcumin at such micromolar concentrations to the site of tumors". Maybe, new formulations with liposomes or nano-encapsulation are likely to bring this promising natural product to the top of therapeutic agents (3).

\section{REFERENCES}

1. Aggarwal BB, Sundaram C, Malani N, Ichikawa H: Curcumin: the Indian solid gold. Adv Exp Med Biol. 2007; 595: 1-75.

2. Santel T, Pflug G, Hemdan NY, Schäfer A, Hollenbach M, Buchold M, et al.: Curcumin inhibits glyoxalase 1: a possible link to its anti-inflammatory and anti-tumor activity. PLoS ONE. 2008; 3: e3508.

3. Wang D, Veena MS, Stevenson K, Tang C, Ho B, Suh JD, et al.: Liposome-encapsulated curcumin suppresses growth of head and neck squamous cell carcinoma in vitro and in xenografts through the inhibition of nuclear factor kappaB by an AKT-independent pathway. Clin Cancer Res. 2008; 14: 6228-36.

Dr. Gerd Birkenmeier Institute of Biochemistry School of Medicine, University of Leipzig Leipzig, Germany

E-mail: Gerd.Birkenmeier@medizin.uni-leipzig.de 